Published in Journal of business strategy, 2017, vol. 38, no. 1, pp. 14-21, which should be cited to refer to this work

Leveraging individual social networks

\title{
BALANCING PRESENT NEEDS AND FUTURE OPTIONS: HOW EMPLOYEES LEVERAGE SOCIAL NETWORKS WITH CLIENTS
}

\author{
Emmanuel JOSSERAND \\ University of Technology Sydney, Sydney, Australia
}

Achim SCMITT

Ecole hôtelière de Lausanne, HES-SO // University of Applied Sciences Western Switzerland

Stefano BORZILLO

Ecole hôtelière de Lausanne, HES-SO // University of Applied Sciences Western Switzerland

\begin{abstract}
This paper applies a social capital perspective to study how business units leverage individuals' external networks to explore and exploit resources outside the firm's boundaries. We explore this matter inductively by analysing the development and leveraging of social capital at the business unit level in a global commodity company. Our findings show how individuals' strong and weak network ties support business unit ambidexterity. We also explore the characteristics of the supportive organisational context that allows firms to reap the benefits of their employees' external social relationships. This study deepens our understanding of exploration and exploitation at both the individual and business unit levels and contributes to research on contextual ambidexterity.
\end{abstract}

\section{Keywords:}

Exploitation, exploration, ambidexterity, social capital, networks, business unit. 


\section{Introduction}

Firms' ability to be ambidextrous - that is, to strike a balance between exploiting their current competences and exploring future competences - is considered crucial for organizational prosperity (e.g., Simsek, 2009; Raisch, Birkinshaw, Probst and Tushman, 2009; Wang and Rafiq, 2012). In the past, research explored the ambidexterity hypothesis (He and Wong, 2004), as well as its antecedents and moderators (e.g., Raisch and Birkinshaw, 2008). Recently, scholars have become increasingly interested in the simultaneous pursuit of exploitation and exploration at the business unit level (Jansen, Simsek and Cao, 2012; Simsek, Heavey, Veiga and Souder, 2009; O’Reilly and Tushman, 2008). According to Gibson and Birkinshaw (2004), unit ambidexterity characterises a business unit’s capability to exploit its existing markets, competences and resources' value, while simultaneously exploring new products, markets and opportunities. However, prior research has only started to explore how ambidexterity is created at the business unit level (e.g., Jansen et al., 2012; Wang and Rafiq, 2012).

Since social capital uncovers relationships that give access to exploit and explore resources and opportunities (Payne, Moore, Griffis and Autry, 2011; Adler and Kwon, 2002; Nahapiet and Ghoshal, 1998), researchers have started to explore its role in achieving ambidexterity. Some scholars have suggested that individual social capital is critical for firm ambidexterity (e.g., Jansen, Van den Bosch and Volberda, 2006; Mom, Van den Bosch and Volberda, 2009), but others (e.g., Lechner, Frankenberger and Floyd, 2010; Vanhaverbeke, Gilsing, Beerkens and Duysters, 2009) have shown rather task-contingent effects. Given these findings, more research is needed into social capital's role in achieving ambidexterity (e.g., Mom et al., 2009; Simsek, 2009). Extant research has analysed intra-firm and inter-firm relationships’ roles in achieving ambidexterity (e.g., Burgers, Jansen, Van den Bosch and Volberda, 2009; Mom et al., 2009; Simsek, 2009). However, no study has uncovered 
individual, external social capital's role in achieving ambidexterity at the business unit level. This is surprising, given business units' critical role in identifying and implementing business opportunities (Floyd and Lane, 2000). Following recent calls from social capital (e.g., Payne et al., 2011) and unit ambidexterity research (e.g., Jansen et al., 2012) to uncover the microfoundations of exploratory and exploitative learning, we use a social capital perspective to explore the liaison between individual external social relationships and business unit ambidexterity.

Understanding the role of individual external social capital for unit ambidexterity requires insights into how individual and organizational social capital interact (Kang and Snell, 2009; Payne et al., 2011). We therefore undertake an exploratory case study of ComInt, a global commodity firm based in France that has successfully leveraged its external social capital, resulting in business unit ambidexterity. Based on the results of 33 interviews, our findings indicate that the exploration and exploitation of external networks at the individual level are complementary processes that provide the basis for exploration or exploitation activities at the business unit level. We thus contribute to social capital literature and research on business unit ambidexterity. In addition, our results contribute to extant contextual ambidexterity research by specifying the conditions that help firms develop and leverage individual, external social capital for exploration and exploitation.

\section{Unit ambidexterity}

Ambidexterity refers to the ability to reconcile exploitation and exploration's internal tensions and conflicting demands (Raisch and Birkinshaw, 2008). These tensions arise because exploitation aims to leverage existing capabilities and knowledge stocks through refinement, efficiency, selection, and implementation, whereas exploration aims to create future capabilities outside current knowledge domains via variation and creativity (March, 
1991; Cepeda-Carrion, Cegarra-Navarro and Jimenez-Jimenez, 2012). The simultaneous pursuit of exploitation and exploration improves business units' performance (Cao, Gedajlovic and Zhang, 2009) by combining existing markets' development and the creation of entirely new revenue sources (Jansen et al., 2012).

The capacity to simultaneously strive for exploration and exploitation stems from a behavioural context that allows employees to divide their resources adequately between the two activities (Gibson and Birkinshaw, 2004). Contextual ambidexterity refers to the mostly invisible set of stimuli and demands that can shape individual and collective behaviours towards ambidexterity (Ghoshal and Bartlett, 1997). Previous studies argue that contextual ambidexterity stems from leaders with a complex behavioural repertoire (Lewis, 2000), the creation of shared vision (Bartlett and Ghoshal, 1989), organizational culture (Gibson and Birkinshaw, 2004), established communication patterns' perturbation (Brunner, Staats, Tushman and Upton, 2009) and the use of meta-routines and job enrichment schemes (Adler, Goldoftas and Levine, 1999). However, some researchers (e.g., Lavie, Stettner and Tushman, 2010; Wang and Rafiq, 2012; Jansen et al., 2012) have recently emphasized that little is known on how to establish such a supportive context at the business unit level. Given business units' critical role in pursuing business opportunities and linking individual and organizational levels throughout the organization (Floyd and Lane, 2000), our study focuses on the business unit's contextual conditions for achieving ambidexterity.

\section{A social capital perspective on ambidexterity}

Parallel to contextual ambidexterity research, scholars have started to uncover the social capital's role regarding "understand[ing] the 'trade-off' between exploration and exploitation” (Kang and Snell, 2009: 67). If we consider firms as social groups that combine and transform individual and social expertise into economically valuable outputs (Kogut and 
Zander, 1992), employees’ social relationships become a valuable resource for organizational activity (Nahapiet and Ghoshal, 1998). Consequently, social capital - characterised as distinctive knowledge stocks embedded in and distributed through individuals' external and internal relationships (Adler and Kwon, 2002) - is a potential source of ambidexterity.

Social capital entails the relationships between actors (Nahapiet and Ghoshal, 1998), which can be analysed in terms of their structural, relational, and cognitive dimension (Granovetter, 1992; Adler and Kwon, 2002). The structural dimension (embeddedness) characterises the overall connection between actors in a social network (Maurer and Ebers, 2006). Conversely, social capital's relational dimension describes the nature of personal ties built through a history of interaction. It encompasses all elements (i.e. shared norms, trust, understanding) that shape and determine the relationship (Nahapiet and Ghoshal, 1998). Finally, the cognitive dimension concerns the shared systems of meaning, representation and understanding among individuals (Kang and Snell, 2009). Additionally, research has distinguished between social capital's internal and external social network dimensions (Payne et al., 2011).

Ambidexterity research has emphasized internal relational embeddedness’s facilitating role in exploitation and exploration (Jansen et al., 2006; Mom et al., 2009; Taylor and Helfat, 2009). Social capital enables firms to increase their internal connectedness, which helps them explore new technologies while exploiting existing capabilities (Taylor and Helfat, 2009). Conversely, other scholars (e.g., Lechner et al., 2010; Reagans and Zuckerman, 2001; Harryson, Dudkowski and Stern, 2008) argue that the firm's social relationships have more task-contingent effects. These studies consider weak internal network ties as beneficial for exploration by providing access to non-redundant knowledge and strong network ties as a condition for knowledge sharing and exploitation (e.g., Hansen, 1999). 
Previous ambidexterity studies (e.g., Hoang and Rothaermel, 2010; Tsai, 2001) and entrepreneurship research (e.g., De Carolis and Saparito, 2006; Liao and Welsch, 2005) emphasized inter-firm networks' role in achieving ambidexterity. For instance, scholars have argued (e.g., Lin, Yang and Demirkan, 2007) that external social capital helps firms pursue exploration or exploitation (e.g., Lin et al., 2007) by offering access to novel ideas (Inkpen and Tsang, 2005) and complementary knowledge outside a firm’s boundaries (Taylor and Helfat, 2009). While some researchers have argued that a given inter-firm relationship can either have an explorative or exploitative character but not both (e.g., Koza and Lewin, 1998; Vanhaverbeke et al., 2009), others (e.g., Im and Rai, 2008; Lavie and Rosenkopf, 2006) found that exploration and exploitation can emerge from the same external relationship. Consequently, Simsek (2009) has called for more research on external social networks' role in achieving ambidexterity.

According to Payne and colleagues (2011), gaining more insights into the impact that lower levels of analysis (such as individuals) have on higher levels (such as groups or organizations) is a promising approach to better understand the role that social capital plays in ambidexterity. While business units play a critical role in achieving ambidexterity (Cao et al., 2009), studies analyzing the relationship between social capital and business unit ambidexterity are scarce. Jansen and colleagues' (2006) study - one of few to address this question - highlights that high internal network ties enable firms to balance and resolve the conflicting tasks of exploitation and exploration within a business unit. To our knowledge, no study has explored individual, external social network’s role in achieving unit ambidexterity.

This paper aims to fill this gap by exploring (a) individual, external social capital's role in exploitation and exploration activities at the business unit level and (b) the appropriate mechanisms and conditions that allow business units to nurture and leverage these relationships. Our study focuses on social capital's relational dimension. Prior internal social 
capital research has emphasized this dimension as critical for achieving ambidexterity (Kang and Snell, 2009). The dimension can be characterized in terms of the strength of the ties resulting from a combination of time, emotional intensity, and intimacy (Granovetter, 1973). It is thus an indication of how well an individual knows his/her exchange partner (McFadyen and Cannella, 2004). Their interactions build the foundation that allows an individual to access and leverage resources and knowledge embedded in these relationships. In line with Payne and colleagues' (2011) suggestions, we model individual, external social capital's effects (lower level of analysis) on business unit level ambidexterity (higher level construct).

\section{Research design}

This study follows a single case study design with the analysis positioned at the individual and business unit levels. This study design was chosen as it provides insights into contextual conditions and thus creates a deeper understanding of cause and effect relationships (Gibbert, Ruigrok and Wicki, 2008). Our aim was to develop insights from field-based case data by following the principles of theory elaboration (Lee, Mitchell and Sablynski, 1999), which extends existing theory (on unit ambidexterity) and builds on pre-existing conceptual ideas that drive the research. The use of theory is limited to defining the research issues and essential concepts (Eisenhardt, 1989), such as individual and collective external social capital, exploration, exploitation and ambidexterity. We then progressively built theory by adding new insights from the literature. The emerging patterns gradually led to new theoretical insights (Guba and Lincoln, 1994) into individual, external social capital and organisational ambidexterity.

\section{Research setting}

The selection of the company - which we call ComInt - emerged after three initial interviews 
that indicated the development of local networks as a key business unit success factor. ComInt is one of the world leaders in the gas industry. Since its founding more than a century ago, natural gases (oxygen, nitrogen, hydrogen) and rare gases have been at the core of the firm's activities, producing a range of commodities for large industry customers and sole traders. While the main resources (gas) have not changed over the years, the firm has constantly relied on innovation to explore new markets, develop and exploit its industry, and create new customer solutions. The company is present in more than 80 countries. Europe is responsible for $50 \%$ of the group's turnover, while North America and Latin America account for 22\%, Asia and Australia for 25\% and Africa for 3\%. The firm's nearly 50,000 employees work in four distinct divisions producing products and services for a broad range of distinct industries: Industrial Merchant, Healthcare, Large Industries and Electronics. Each division contains business units responsible for a specific geographical zone. We analysed three business units situated in France and in the Industrial Merchant division. This branch is responsible for two-thirds of the entire group’s activity.

\section{Data collection}

The primary data source was a total of 33 semi-structured interviews lasting between one and four hours at different organisational levels (ranging from top-level management to production workers). We had access to three regional business units. One was researched extensively, while the other two were used to ascertain our results' internal validity by assessing whether our observations of the first unit could be extended to other organizational units. Although there were differences between the individual relationships, which are detailed below, the nature of our results was comparable at the business unit level. Table 1 shows the list of interviews and the interviewees' positions. The interviews addressed the links between the individuals in the business units and the external actors. We also collected 
information about the strategic objectives, the local competitive environment and work organisation. Open-ended questions were used to allow the interviewees to freely relate their network development anecdotes. In particular, we asked our respondents to identify key external actors with whom they interacted and to describe the corresponding relationships.

Our interviews were supplemented with a sociometric survey in two business units. Our interviews with business unit members at different levels do not allow us to draw conclusions regarding all the employees. However, the surveys allowed us to gain additional perspectives on the overall network and thus do not limit our observation to the interviewees' networks. By corroborating the interviewees' indications, the surveys also allowed triangulation. Building on Scott's (2000) distinction, we analysed several external social networks: work contact, control, influence, help/advice and trust (see the Appendix for the detailed questions). This classification helped us better understand the individual social networks' nature. A list of external actors - representing broad categories such as suppliers, customers and competitors - was used as a prompt. We tested our interview questionnaires qualitatively before administering them. By exploiting the complementarities between the qualitative and quantitative data, we followed the recommendation that a multilevel contextualising method should be adopted when studying networks (Lazega, 1997).

Supplementary sources of evidence, such as documents and in-the-field presence were also used. We visited several locations and requested a guided tour of the premises (the office and plant) during the first visit. This provided an opportunity for a preliminary, informal conversation with the staff. We also attended four on-site internal meetings. Several short interviews (under an hour) were mainly conducted with lower-level employees.

Insert Table 1 about here 


\section{Data analysis}

The conceptual contribution emerged from a two-step process. The first data analysis stage was conducted in parallel with the data collection. Transcripts were prepared the same day or the week after the interview. After analysing each transcript, we coded the content according to very broad categories. The first category (“business unit organization”) aimed at gaining an understanding of the business unit context and how it supported individual social capital's development and leveraging. For instance, within this category, we classified quotes relating to the commercial team's functioning as described in the results section and its importance in social capital construction and leveraging. An additional set of categories was derived from our literature review and built on the basic social capital concepts. These were: "interactions with other business units ${ }^{1}$ ”, “strong ties with external actors”, "weak ties with external actors" and "resources derived from these interactions". The third category was used to code the quotes relating to ambidexterity. Some of the resources contributed to exploitation and others to exploration. We included two emerging categories relating to the strategic context after a first series of interviews: “need for local adaptation” and "need for integration”. We noted the emerging concepts that needed confirmation or further investigation in follow-up interviews. This led us to gradually refocus the interviews and conceptualise the emerging categories (Miles and Huberman, 1994), thereby facilitating the final data analysis.

After consolidating our interviews, we drafted a 71-page case study, identified subthemes and gradually refined the emerging categories. This document also included a sociometric analysis. Using our multi-level approach, we started consolidating information about the first unit's individual networks, their impact at the business unit level in terms of exploration, exploitation and the contextual conditions. We also consolidated information about organizational issues, problems or limitations. The results were then compared with

\footnotetext{
${ }^{1}$ This category also included the interaction with central units. It provided information about the business unit context. For instance, the principle of the business unit autonomy was allocated to this category.
} 
those of the two other units. While differences were observed between individuals, the networks' nature, the business unit context and the resulting ambidexterity were comparable between the three units. We thus use quotes from the three units in the result section. Finally, we ensured internal validity by submitting the document to a top manager, an operational manager and two business unit managers. The senior executive also commented on the paper’s draft version.

\section{Findings}

The case study analyses the interrelationships between the employees' external social capital and the business units' exploitative and explorative activities at ComInt.

\section{Analysing the foundations of external social capital}

We identified individuals’ external social network ties and distinguished between their strong and weak ties. Although we enquired about all types of external ties, our interviewees emphasized that external client relationships play a critical role in the business units' performance. We thus focus on external client relationships.

Strong ties and key actors. Our interviews identified a group of actors who emerged as central to the business unit's social capital. Strong ties with the firm's two main customer groups (clients and prescriptors) characterised this group. All our interviewees continuously emphasised the importance of the group's strong external relationships. These strong ties emerged from constant working relationships that developed over time. When asked about the nature of their links with external actors, the respondents typically described the connection as "quality”, "trust” or "partnership". In this respect, an engineer indicated that “[the] foundations of our client relationships are based on trust”.

During the interviews, we found that strong ties exist at different hierarchical levels and 
concern operational (sales, after-sales, technical) and functional issues (accounting, service). At the operational level, these frequent interactions are formalised in a multi-functional team (an accountant, a technician and a salesperson) that monitors and nurtures the firm's client relationships on a daily basis. This team regularly exchanges information about clients, considers options to improve the overall client relationships and provides the firm with a better understanding of the clients' specific needs and reasoning. All members of the team have their own contacts, who deal with different issues, in the client firm. Frequent exchanges with clients enable technicians not only to understand specific demands, but also to sell their technical expertise and gain the client's trust. Hence success is based on the capacity to understand customer needs and gain their trust regarding various aspects. While technicians are expected to have close connections, it is rather novel for accountants. The interviewees explained that when problems with payment or invoices arise, these close connections could help solve them quickly and thus contribute greatly to maintaining the relationship. An accountant noted: "We [the accountants] know some clients very, very well and understand their needs and reasoning. Even if there are no problems we go and see them and then things go much more smoothly".

Besides the multi-functional team, ComInt has established a parallel network of technical experts. Each region has one or several technical experts who are encouraged to develop local network ties with firms for which ComInt functions as a supplier (“prescriptors"). Owing to fierce competition in this industry, superior technical knowledge and expertise are fundamental elements of doing business with the prescriptors. The technical experts repeatedly emphasised that strong social connections to prescriptors are a precondition for a successful business relationship. A technical expert reported: “There must be a relationship of trust and sympathy to be successful in this business”.

In all three business units, we found a relatively limited group of actors who are crucial 
for managing the external client relationships. These relationships are based on frequent exchanges between various key employees and clients, which allow the development of trust and shared reasoning over time. In addition, this group of employees has strong mutual network ties and regularly discusses customer satisfaction and operational performance.

Weak ties. Nevertheless, the relationships with the external actors are not limited to actors connected via strong ties. While the client team's mains focus is on key accounts, they are also often connected to other clients via weaker ties. These exchanges occur more sporadically. In addition, ComInt's business units comprise employees who are weakly connected to clients and/or the client team. This group of employees activates its networks less frequently, interacts with external clients under specific circumstances (i.e. problems, technical expertise), assists the client team and is encouraged to develop its own ties with customers. While these relationships are fairly ad hoc, they are important for the firm's overall functioning. In this respect, a regional director indicates: "Everybody has to become involved in the clients' demands and needs to contribute to respond to their needs... everybody fulfils a specific role in the client relationship".

These irregular social interactions occur in all functions and at all hierarchical levels in the business unit. Weak ties contribute greatly to the development of the overall client relationships. At ComInt, employees who occasionally interact with external stakeholders either provide the basis for the client relationship's future development (i.e. transformation from a currently weak to a future strong relationship), or they help colleagues maintain their current strong client relationships. A good illustration of this is the role played by a Security Manager in one of the region. During a conversation with one of his commercial colleagues, the idea emerged to offer security training sessions for some of the clients at industrial sites. This would increase the company's visibility and strengthen the relationship with the customer. The idea was then proposed to other multi-functional teams and implemented with 
many customers. He explained the role division in these security trainings: "My client's trainings are provided at the request of the commercial [colleague]... he is in charge of the relationship, but I provide the training”.

The objective is that all employees not only contribute to the client relationship, but also develop a general sense of the firm's desire to become a client-driven organisation. This creates a shared identity among employees and provides clarity regarding each individual's role within the business unit. A business unit's regional director considered this as vital to successfully respond to client demands: “[These relationships] improve reactivity, allow customer proximity and improve the overall contact."

Weak ties also lead to diversity in the client relationship. Occasional interactions on various functional aspects shed light on new ideas and provide solutions for existing problems. Such interactions stimulate thought, help identify problems, and thus improve the overall client satisfaction. For instance, we had several stories of drivers contributing by collecting information or answering clients' queries. Drivers refill the cryogenic tanks or deliver gas bottles and thus have frequent interaction with the clients' personnel. Moreover, drivers meet different actors - for instance, first level employees with whom the multifunctional teams have very little interaction - daily. Consequently, they may have practical questions or information that can lead to specific client needs being identified. For instance, a plant foreman at a business unit reported: "It often happens that a driver comes up with a question from a client. This helps to improve our client relationship”.

Our interviews clarified that the vast majority of the business unit's employees were somehow involved in contributing to the customer relationships through weak ties.

Summary of individual social networks. Individual, external social capital at ComInt's business units comprises a mix of strong and weak network ties. Strong network ties exist at the direct or indirect interface with clients. Our sociometric data analysis confirms that only a 
few employees (27\%) in ComInt's business units engage regularly in strong external network ties (characterised by multiplex social networks based on contact, control, influence, help/advice and trust). These employees are the sales and technical employees as well as the regional manager. Conversely, weak ties fulfil an important support function that bridges the existing knowledge gaps in the strong network ties. They appear sporadically and often focus on a particular issue. The results from our sociometric data indicate that $93 \%$ of the employees of business units are connected through weak network ties to a social network that manages the client relationships (see Table 2). While being recurrent, such ties are operational contacts that do not encompass relationships characterised by control, help/advice or influence. This overall picture of the network thus corroborates the findings from the interviews.

Insert Table 2 about here

\section{Business unit exploitation and exploration benefit from individual social capital}

As noted above, each business unit contains a network mix of strong and weak ties. This section describes how individual network connections provide access to knowledge that can translate into potential leads for exploitation and exploration at the business unit level.

Exploitation benefits. At the business unit level, the exploitation benefits of individual social capital are threefold: commercial leads, repeated business and value added services.

Commercial leads are based on organisational information benefits that mainly concern future projects, local resources and competition. While weak ties can occasionally provide commercial leads, information benefits emerge mainly from the client relationship teams and the technical experts who gather commercial and competitive information through their strong customer ties. For instance, a technical expert who obtained good commercial leads in 
the past insisted on reciprocity and trust: "Prescriptors are a source of information but it only works if there is an exchange of information. There must be a relationship of trust and sympathy." Once a lead has been identified (whether with a customer or a prescriptor), the commercial team analyses and evaluates the information and decides upon action. Owing to the autonomy granted to internal actors and the tight connection between them, decision making is swift and allows for a quick reaction to customer requests.

Repeated business is anchored in trust benefits based on individual client relationships. Such trust benefits result from previous working relationships’ quality. Strong network ties are thus important to generate repeated business operations with a customer. Moreover, the embeddedness of strong ties is also critical to ensure the client's quality perception. The following quote illustrates the respective roles of strong and weak ties: "The objective is to provide information and advice. The aim is that when they need something, they will buy from ComInt. This is especially important in a context where competition is fierce. Weaker connections [...] will then contribute to creating a strong image of quality of service, which will have an impact on the decision" (Technician).

However, the impact is not only on the volume, but also on the nature of sales. One of ComInt's key competitive advantages is its capacity to provide tailor-made services and not only commodities. This requires close interactions with customers, which is based on strong partnerships over time. A commercial manager mentioned: “The relationship is one of partnership rather than one of sales... it is all about our clients being partners in order to develop customised services. It is not a commodity. We learn and adapt our products to [our] clients over time”. Such value added service outcomes are key for the corporate strategy as they help to shift the organisation from a commodity provider to a client-driven service organization. A commercial manager at ComInt indicated: "The only way to detect the need for a new service is to know our clients' processes as well as the client fully". 
Exploration benefits. Another benefit of employees' external social capital is local, autonomous innovations. Several core mechanisms encourage the development of new services or products with the client. For instance, when members of the commercial team have identified a new customer need, they can freely access experts and central corporate resources to research potential solutions with the client. Industry experts are either situated in the region, or divide their time between several regions, and report to one of the national development centres. If necessary, the client is invited to participate in an experiment at a development centre. However, the individual or team who established the client relationship remains the project leader. In this sense, technical experts and development centres function as a support service dedicated to local innovation. A regional director mentioned: “The objectives of these units are the sum of the regions' objectives; they thus have a strong incentive to work intelligently with the regions”.

Local innovations range from the new usage of an existing product to service innovation, or even the opening of a new market. A few examples at ComInt include the development of automated distance stock monitoring, supply chain tagging and the French region Manicourt, which established a Formula 1 Grand Prix. For instance, a distance monitoring system that monitors the stock of bottles was invented after a discussion between a technician and his counterpart at the customer. The client was a key account and both individuals had a strong on-going relationship. Their idea emerged from an existing technique to monitor stocks for much larger gas storage in cryogenic containers. The technicians set up a team with engineers from a national development centre and created a bottle-monitoring system based on magnetic cards. This was implemented throughout the region and other business units. It is important to note that such local innovations often create interdependencies with the client organization. Pre-existing trust is thus central - not only to detect the need but also for the customer to accept the risk associated with more 
interconnected processes. A regional director notes: "They [the clients] need to trust us as their success depends on the quality of our work". These local innovations have proven extremely fruitful. A central R\&D team director declared: “An increasing number of units are innovating with customers; an increasing number of ideas have emerged from the field. Innovations can be about new services, new products or a new market. Many new products have been created in the regions".

Our data indicates that the combination of strong and weak individual ties has specific impacts on both exploration and exploitation, thus favouring ambidexterity. On the one hand, commercial leads - one of the exploitation benefits - can be derived regularly from strong ties, but also occasionally from weaker connections. Repeated business is favoured by strong ties, whereas weak ties function as a support system. This structure also favours the development of value added services, which capitalize on strong embedded interpersonal ties. On the other hand, exploration benefits stem from strong ties that create opportunities for local innovations. Such innovations often imply a further increase in the connectedness between the client and ComInt's processes and are then generalized in the business unit.

\section{Facilitating individual social capital}

Individual social network connections constitute very specific mixes of strong and weak external ties. These networks can flourish due to specific contextual conditions established in the business units: autonomy, network culture and organised redundancy.

Autonomy. Autonomy emerged in the interviews as a key condition for the development of the networks underlying social capital. Autonomy at ComInt concerns not only managers, but all of the business unit's functions and levels. For instance, each business unit can almost be considered an independent company linked to a global group. Regional directors benefit from a very important margin for manoeuvring, including on financial matters: “There are 
really very few exceptions to my delegation of power [autonomy] and these relate to very specific contracts” (Regional Director).

Such autonomy is reflected in the way functional departments intervene: they consider it their role to provide support rather than give directives. For instance, ComInt's functional departments are often seen as "super-experts". In addition, the structure of each unit allows everybody to develop networks. For instance, the organisation enables small multi-functional teams to take appropriate action to maintain good relationships with a group of clients: "The structure gives small teams the power to take decisions” (Regional Director). This helps keep the units' actors focused on developing relationships with local external actors. The interviewees explicitly linked autonomy with the need to adapt to local clients and to local market conditions. Individuals are free to propose a new product or service for their business unit. For example, “The group provides us with resources, but it is up to each business unit manager to use these resources according to the needs of each customer. They are the only ones who know their customers well enough to be able to do this” (Operational Director).

Flexibility in relation to local clients' need is very important. Autonomy is visible on all hierarchical levels and characterised by a very flat structure of only two hierarchical levels in the business units. Operators have an important freedom that allows them to independently manage their activity and tools. One operator gave us examples of such organisational independence: "I needed parts for my machine: I ordered and then discussed them. When my machine leaked, I directly asked the supplier to send someone to fix it." Similarly, another operator indicated: “We don't lose time when processing information. There are no hierarchical levels involved, which allows direct exchanges with the client's engineers. If there is a problem, I go and look at it right away."

Network culture. Culture plays an important role in stimulating the development of individual networks. HR and communication tools are used to help promote a network 
development culture, whether in recruitment, training or communication events. The importance of external local networks is therefore a recurring theme that is widely communicated to the personnel. The company focuses on two communication themes linked to local network development: “development of clients and proximity services” and “initiative in the field”. Such messages are constantly used in top management discourses, local managers' presentations, during training sessions as well as at global and local communication events. In the company's monthly newsletter, the president's statement reflects this matter. "Our success depends on the relationships with our clients. We need to be constantly reminded of this fact ... we need to systematically remind ourselves of our values and constantly look for and discuss new ways of improving these relationships”.

These relationships were also discussed across the board during the annual evaluation interviews and staff training sessions. Similarly, the following quote from the HR manager illustrates that recruitment is related to the values of a network culture: "We need people who are able to communicate: curious, open, autonomous leaders. They must not be afraid to transmit their knowledge, to communicate laterally... The ideas of sharing and generosity are important". There is thus a strong sense that sharing these values is extremely important for the organisation. A manager mentioned the following about the internal employment forum: "People already in the organisation are the guarantors of the current culture."

Organised redundancy. The third condition for the organisation's use of individual social capital is the clear division of roles between the actors to align individual network development with the organisational needs. Since this encourages all actors to develop their networks, several at ComInt may be in contact with the same external institution (e.g., a client organisation). Such repetitions, which are built into the sub-units' structure, lead to organised redundancy in which the relationship distribution and the combination of strong and weak ties are carefully managed. At ComInt, these redundant networks are organised 
according to the hierarchical levels and functions, which all the actors understand well. For instance, the responsibilities in the commercial function are clearly established at each level. The regional director communicates with the heads of local companies, while the other actors work at another level. A regional director explained: "I meet with the clients as often as possible so that these entrepreneurs, who are used to seeing different levels, continue to have several interlocutors”.

In the commercial multifunctional team, network division also occurs by function at a lower level, ensuring a clear delineation of responsibilities. The commercial actors focus on strong ties that will lead to repeated businesses, while technicians provide technical help and advice. A salesperson noted: “Our objective in the relationship is a sales objective. It's all about having good relationships with customers in order to sell more”.

Relationships are thus partially redundant, which allows the external networks to be activated when needed across functions and levels. This maximises the opportunities to obtain the expected results in terms of exploration and exploitation. The redundancy of connections can be used to access resources, protect existing relationships, and/or repair damaged ones. This occurs, for example, when an accountant avoids commercial tension through sound payment management. Redundancy of ties is thus carefully managed at the business unit level through a clear division of roles, which corresponds to a hierarchical and functional distribution of relationships.

\section{Difficulties and limitations in implementation}

While the networks' nature, the business unit context and the resulting ambidexterity were comparable between the three units, our interviewees underlined individual differences and implementation limitations.

Individual difficulties. Our interviewees emphasized the importance of autonomy if 
networks are to be developed; however, the implementation of autonomy was not always flawless. For instance, in one region, the director had been recently appointed. He underlined that his predecessor had not coped well with the idea of a strong autonomy within the region. He also mentioned other cases where this had happened with two different outcomes: either a strong hierarchy was reintroduced into the region, or the director tried to take all decisions directly. He summarizes the situation as follows: "Some regional directors were sceptical and recreated a mini-hierarchy. Other bosses had chosen to make all the decisions, whereas only competences count." Such negative individual reactions were observed at various levels in the structure and regarding various functions. Our interviewees described autonomy as an individual element not connected to a specific region - examples were quoted in the three regions but regarding different roles or positions. Increased autonomy can be destabilizing for bosses and does not necessarily results in more employee motivation. A technician summarized the issue well when he said: "There are people who know how to work autonomously, others don't; whatever the level. Some operators are excellent at making decisions regarding their job; others are high level salespersons who systematically seek approval from the regional director." This issue resulted in some people leaving the company. To avoid the tension that the autonomy induced in bosses and employees, a system of mentoring was implemented that helped individuals cope and thus reduced the difficulties of implementation.

Trade-offs regarding costs. A second limitation of the contextual conditions implemented at ComInt is that of the balance between the different exploitation objectives. While there is a clear exploitation objective in terms of an increased turnover due to the provided service's qualitative improvement and repeated businesses, several interviewees mentioned a trade-off in terms of costs. One of the key elements relates to the regions' autonomy and the capacity to control their production tools. This means, for instance, that gas 
is still extracted in concentrated units outside the regions, but that they can now fill their own gas bottles. This provides flexibility but increases the cost per unit. This is a very conscious strategic choice. One of our interviewees from the headquarters indicated: "The regional structure performs less well in terms of production but brings new developments." There is thus a clear strategic trade-off in favour of flexibility and innovation that has an accepted negative impact on costs while supporting exploitation in terms of higher value services.

\section{Discussion}

In this study, we analysed how business units build on an individual, external social capital to explore and exploit the resources available in their environment. While prior research theoretically analysed internal social capital's benefits regarding achieving ambidexterity (e.g., Kang and Snell, 2009), our results provide insights into how individual, external social capital can lead to exploitation and exploration activities at the business unit level and to the contextual conditions conducive to its development.

We found that the social capital developed at the individual level contributed to both exploration and exploitation at the business unit level. In particular, our study emphasized the role that embedded strong network ties play in exploitation. Moreover, such strong network ties also open new explorative avenues. Weak ties mainly have a support function, assisting strong network ties regarding exploitation. In addition, we found that developing and leveraging individual social capital requires a specific organisational context that gives the business unit access to individual social capital outcomes. These conditions are: autonomy, a network culture and a clear distribution of strong and weak ties through organised redundancies. Figure 1 summarises these findings in an integrative model.

Insert Figure 1 about here 
Our results make three theoretical contributions to the extant literature.

First, we contribute to prior research, arguing for a more fine-grained distinction of the task-contingent social capital effect of exploration and exploitation (e.g., Lechner et al., 2010). Previous research (e.g., Hansen, 1999) has argued that internal weak ties provide access to non-redundant knowledge sources and support exploration. Conversely, strong internal ties form the basis of efficient knowledge sharing and provide the basis for exploitation (Reagans and Zuckerman, 2001). Our results show that strong external ties not only enable exploitation, but also provide the basis for exploration. Business unit exploration is essentially dependent on strong ties that will lead to the capacity to create new knowledge with external actors. Related to this, we found that weak ties play a very important support role in exploiting activities. A first possible explanation for these findings is that our research concerns external social capital while former research focused on internal social capital at the business unit level. However, we feel that a more generic theoretical explanation lies in the nature of the targeted exploration and exploitation activities. On the one hand, our results indicate that strong ties are essential in contexts in which exploration activities are dependent on access to sensitive information and/or collaboration. This does not necessarily contradict prior findings that have indicated a positive relationship between weak ties and exploration (Hansen, 1999), but shows that these previous findings only hold in cases where exploration is more dependent on accessing existing knowledge than on the collaborative co-construction of new knowledge. On the other hand, we underline the weak ties' support role in exploitation based on high quality services. This result nuances the emphasis on strong ties for exploitation and reintroduces the importance of the strength of weak ties (Granovetter, 1973). Moreover, our results related to exploitation also stress the high costs related to a certain degree of flexibility that is necessary to maintain external strong ties. This may indicate that the strong and weak ties' role for exploitation may change in light of the 
exploitation's objective (i.e. efficiency vs. quality). These findings contribute to a better understanding of the combination of weak and strong network ties (Im and Rai, 2008; Lin et al., 2007) that enables business units to access and facilitate external knowledge exchanges that can lead to ambidexterity in a specific context. Uncovering such network dynamics between weak and strong ties sheds light on the individual foundations of explorative or exploitative purposes (Koza and Lewin, 1998; Lin et al., 2007; Lechner et al., 2010).

Second, our findings enhance our understanding of the antecedents of business unit ambidexterity (Jansen et al., 2012; Wang and Rafiq, 2012). Prior research has argued that contextual ambidexterity builds on 'enabling bureaucracies' (Adler et al., 1999) that adapt, align and combine individual networks and knowledge effectively (Kauppila, 2010). Our case study reveals three contextual conditions for such a combinative approach at the business unit level: autonomy, network culture, and organised redundancy. The balance between autonomy and control witnessed at ComInt emphasises the importance of creating a certain degree of autonomy for exploration - and, more specifically, for developing individual networks - and the importance of support and control, which ensure proper exploitation. Our findings contribute to prior research on individual employee involvement in contextual ambidexterity (Güttel and Konlechner, 2009) by emphasizing autonomy’s role in creating and maintaining individual, external social networks. By doing so, we respond to calls (Gibson and Birkinshaw, 2004; Simsek et al., 2009; Wang and Rafiq, 2012) to uncover how organizations are able to create contextual ambidexterity based on a bottom-up approach that requires individual participation.

We also show that a network culture is important for social capital development. Prior ambidexterity research has argued that a strong culture constrains exploration and fosters inertia (Lavie et al., 2010). At ComInt, the firm's client-driven focus is based on employees recognizing the benefits of developing and nurturing their own social capital. This helps them 
resolve client tasks and demands and in turn contributes to establishing a network culture. In this sense, we confirm prior suggestions of a positive relationship between a shared organizational context and exploration (Ravasi and Schultz, 2006). We extend these suggestions by indicating a simultaneous positive effect on exploitation. These findings expand the idea of meta-routines, which not only seek to facilitate the performance of nonroutine tasks (Adler et al., 1999) but also to contribute to business units' exploration and exploitation activities.

ComInt's organised redundancy enabled a certain ambidextrous behaviour among individuals working within the business unit. Each business unit is characterised by a strong functional specialisation in terms of what each individual explores and exploits (i.e. an accountant will explore and exploit a very specific set of networks that differ from those that a worksite manager exploits and explores). If ambidexterity is obtained through the coherent combination of organisational conditions (Gibson and Birkinshaw, 2004), this results in external networks that are organised in such a way that individual-level exploration and exploitation are very effective. Redundancy only exists where it is useful. Instead of structural separation (O'Reilly and Tushman, 2004), organized redundancy allows exploitation and exploration to be embedded within the business units' different entities.

Finally, our results extend prior perceptions of the opposition notion (i.e. trade-off) between two separate elements: exploration and exploitation (Raisch and Birkinshaw, 2008). According to Gibson and Birkinshaw (2004), contextual ambidexterity is rooted in a context that allows employees to independently divide their attention and resources between exploitation and exploration. Our results go further, showing that specific contextual conditions can lead to a situation where individuals don't actually have to arbitrate between exploration and exploitation, but can rather leverage strong ties as a basis for exploration. Instead of a trade-off, we have a situation of complementarity between exploration and 
exploitation. This complementary view of ambidexterity corresponds to an understanding of it that is in line with paradoxical approaches to organisations (e.g., Smith and Lewis, 2011). As expressed in "trialectics" (Ford and Ford, 1994), exploration and exploitation seem to be connected through attraction rather than opposition (Ford and Ford, 1994; Wang and Rafiq, 2012).

While our case study provides implications and contributions, it is not without limitations and research should be cautious about generalising our findings. While our study provides a starting point, future research should confirm our findings in dissimilar contexts to advance our knowledge of contingent effects. Furthermore, our study investigates the relationship between the individual and the business unit analysis levels. While this approach responds to calls to bridge multilevel perspectives in ambidexterity (Simsek, 2009) and social capital research (Payne et al., 2011), we encourage research that explores individual social capital's impact on ambidexterity in the context of inter-organizational collaboration at the corporate/industry level (Lavie, Stettner and Tushman, 2011). Additionally, our study investigated network ties with external clients. While these external relationships are critical for exploitation and exploration at ComInt, future studies need to explore whether or not our results also hold in terms of inter-firm social networks. Prior studies (Casanueva and Gallego, 2010; Batjargal, 2003) have frequently emphasized the an individual network’s performance depends on whether it contains useful resources for the individual and/or the organisation. While our study focused on relational embeddedness, we encourage future research analysing the content, quality, and integration potential of resources available through an individual's external network. Finally, we encourage future studies that translate our integrative model into testable hypotheses for cross-sectional research. 


\section{REFERENCES}

Adler, P., B. Goldoftas and D. Levine (1999). 'Flexibility versus efficiency? A case study of model changeovers in the Toyota production system.', Organization Science, 10, pp. 43-68.

Adler, P. and S. W. Kwon (2002). 'Social capital: Prospects for a new concept.', Academy of Management Review, 27, pp. 17-40.

Bartlett, C. A. and S. Ghoshal (1989). Managing Across Borders: The Transnational Solution., Harvard Business School Press, Boston, MA.

Batjargal, B. (2003). 'Social capital and entrepreneurial performance in Russia: A longitudinal study.', Organization Studies, 24, pp. 534-556.

Brunner, D. J., B. R. Staats, M. L. Tushman and D. M. Upton (2009). Wellsprings of Creation: Perturbation and the Paradox of the Highly Disciplined Organization, Harvard Business School, Cambridge, MA.

Burgers, J. H., J. J. P. Jansen, F. A. J. Van den Bosch and H. Volberda (2009). 'Structural differentiation and corporate venturing: The moderating role of formal and informal integration mechanisms.', Journal of Business Venturing, 24, pp. 206-220.

Cao, Q., E. Gedajlovic and H. Zhang (2009). 'Unpacking organizational ambidexterity: Dimensions, contingencies, and synergistic effects', Organization Science, 20, pp. 781-796.

Casanueva, C. and Á. Gallego (2010). 'Social capital and individual innovativeness in university research networks. ', Innovation: Management, Policy \& Practice, 12, pp. 105-117.

Cepeda-Carrion, G., J. G. Cegarra-Navarro and D. Jimenez-Jimenez (2012). 'The effect of absorptive capacity on innovativeness: Context and information system capability as catalysts', British Journal of Management, 23, pp. 110-129.

De Carolis, D. M. and P. Saparito (2006). 'Social capital, cognition, and entrepreneurial opportunities: A theoretical framework.', Entrepreneurship Theory and Practice, 30, pp. 41-56.

Eisenhardt, K. M. (1989). 'Building theories from case study research.', Academy of Management Review, 14, pp. 532-550.

Floyd, S. W. and P. J. Lane (2000). 'Strategizing throughout the organization: Managing role conflict in strategic renewal.', Academy of Management Review, 25, pp. 154-177.

Ford, J. D. and L. W. Ford (1994). 'Logics of identity, contradiction, and attraction in change.', Academy of Management Review, 19, pp. 756-785.

Ghoshal, S. and C. A. Bartlett (1997). The Individualized Corporation: A Fundamentally New Approach to Management., Harper Business, New York.

Gibbert, M., W. Ruigrok and B. Wicki (2008). 'What passes as a rigorous case study?', Strategic Management Journal, 29, pp. 1465-1474.

Gibson, C. and J. Birkinshaw (2004). 'The Antecedents, Consequences and Mediating Role of Organizational Ambidexterity. ', Academy of Management Journal, 47, pp. 209-226.

Granovetter, M. (1973). 'The strength of weak ties.', American Journal of Sociology, 78, pp. 1360-1380.

Granovetter, M. (1992). 'Problems of explanation in economic sociology'. In: N. Nohria and R. Eccles (eds.), Networks and Organizations: Structure, Form and Action. Boston, MA: Harvard Business School Press.

Guba, E. G. and Y. S. Lincoln (1994). 'Competing Paradigms in Qualitative Research.'. In: N. K. Denzin and Y. S. Lincoln (eds.), Handbook of Qualitative Research. pp. 105 - 117. Thousand Oaks, California: SAGE Publications Inc. 
Güttel, W. H. and S. W. Konlechner (2009). 'Continuously hanging by a thread: Managing contextually ambidextrous organizations.', Schmalenbach Business Review, 61, pp. 149-171.

Hansen, M. T. (1999). 'The search transfer problem: The role of weak ties in sharing knowledge across organizational sub-units.', Administrative Science Quarterly, 44, pp. 82-111.

Harryson, S. J., R. Dudkowski and A. Stern (2008). 'Transformation networks in innovation alliances - the development of Volvo C70.', Journal of Management Studies, 45, pp. 745-773.

He, Z. L. and P. K. Wong (2004). 'Exploration vs. exploitation: An empirical test of the ambidexterity hypothesis.', Organization Science, 15, pp. 481-494.

Hoang, H. and F. T. Rothaermel (2010). 'Leveraging internal and external experience: Exploration, exploitation, and R\&D project performance.', Strategic Management Journal, 31, pp. 734-758.

Im, G. and A. Rai (2008). 'Knowledge sharing ambidexterity in long-term interorganizational relationships.', Management Science, 54, pp. 1281-1296.

Inkpen, A. and E. W. K. Tsang (2005). 'Social capital, networks, and knowledge transfer.', Academy of Management Review, 30, pp. 146-165.

Jansen, J. J. P., Z. Simsek and Q. Cao (2012). 'Ambidexterity and performance in multiunit contexts: Cross-level moderating effects of structural and resource attributes.', Strategic Management Journal, forthcoming.

Jansen, J. J. P., F. A. J. Van den Bosch and H. Volberda (2006). 'Exploratory innovation, exploitative innovation, and performance: Effects of organizational antecedents and environmental moderators.', Management Science, 52, pp. 1661-1674.

Kang, S.-C. and S. A. Snell (2009). 'Intellectual capital architectures and ambidextrous learning: A framework for human resource management.', Journal of Management Studies, 46, pp. 65-92.

Kauppila, O.-P. (2010). 'Creating ambidexterity by integrating and balancing structurally separate interorganizational partnerships.', Strategic Organization, 8, pp. 283-312.

Kogut, B. and U. Zander (1992). 'Knowledge of the firm, combinative capabilities and the replication of technology.', Organization Science, 3, pp. 383-397.

Koza, M. P. and A. Lewin (1998). 'The Co-evolution of strategic alliances.', Organization Science, 9, pp. 255-264.

Lavie, D. and L. Rosenkopf (2006). 'Balancing Exploration and Exploitation in Alliance Foundation.', Academy of Management Journal, 49, pp. 797-818.

Lavie, D., U. Stettner and M. L. Tushman (2010). 'Exploration and exploitation within and across organizations.', The Academy of Management Annals, 4, pp. 109-155.

Lavie, D., U. Stettner and M. L. Tushman (2011). 'Exploration and exploitation within and across organizations.', The Academy of Management Annals, 4, pp. 109-155.

Lazega, E. (1997). 'Network analysis and qualitative research: A method of contextualization.'. In: G. Miller and R. Dingwall (eds.), Context \& Method in Qualitative Research. London: Sage.

Lechner, C., K. Frankenberger and S. W. Floyd (2010). 'Task contingencies in the curvilinear relationships between intergroup networks and initiative performance.', Academy of Management Journal, 53, pp. 865-889.

Lee, T. W., T. R. Mitchell and C. J. Sablynski (1999). 'Qualitative research in organizational and vocational psychology: 1979-1999.', Journal of Vocational Behavior, 55, pp. 161187.

Lewis, M. W. (2000). 'Exploring paradox: Toward a more comprehensive guide.', Academy of Management Review, 25, pp. 760-777. 
Liao, J. and H. Welsch (2005). 'Roles of social capital in venture creation: Key dimensions and research implications.', Journal of Small Business Management, 43, pp. 345-362.

Lin, Z., H. Yang and I. Demirkan (2007). 'The performance consequences of ambidexterity in strategic alliance formations: Empirical investigation and computational theorizing.', Management Science, 53, pp. 1645-1658.

March, J. G. (1991). 'Exploration and exploitation in organizational learning.', Organization Science, 2, pp. 71-87.

Maurer, I. and M. Ebers (2006). 'Dynamics of social capital and their performance implications: Lessons from biotechnology start-ups.', Administrative Science Quarterly, 51, pp. 262-292.

McFadyen, M. A. and A. A. Cannella (2004). 'Social capital and knowledge creation: Diminishing returns of the number and strength of exchange relationships.', Academy of Management Journal, 47, pp. 735-746.

Miles, M. B. and A. M. Huberman (1994). Qualitative Data Analysis., SAGE Publications, Thousand Oaks, California.

Mom, T. J. M., F. A. J. Van den Bosch and H. Volberda (2009). 'Understanding variation in managers' ambidexterity: Investigating direct and interaction effects of formal structural and personal coordination mechanisms.', Organization Science, 20, pp. 812828.

Nahapiet, J. and S. Ghoshal (1998). 'Social capital, intellectual capital and the organizational advantage.', Academy of Management Review, 23, pp. 242-266.

O'Reilly, C. A. and M. L. Tushman (2004). 'The ambidextrous organization.', Harvard Business Review, 82, pp. 74-81.

O'Reilly, C. A. and M. L. Tushman (2008). 'Ambidexterity as a dynamic capability: Resolving the innovator's dilemma.', Research in Organizational Behavior, 28, pp. 185-206.

Payne, T. G., C. B. Moore, S. E. Griffis and C. W. Autry (2011). 'Multilevel challenges and opportunities in social capital research.', Journal of Management, 37, pp. 491-520.

Raisch, S. and J. Birkinshaw (2008). 'Organizational ambidexterity: Antecedents, outcomes, and moderators.', Journal of Management, 34, pp. 375-409.

Raisch, S., J. Birkinshaw, G. Probst and M. L. Tushman (2009). 'Organizational ambidexterity: Balancing exploitation and exploration for sustained performance.', Organization Science, 20, pp. 685-695.

Ravasi, D. and M. Schultz (2006). 'Responding to organizational identity threats: Exploring the role of organizational culture.', Academy of Management Journal, 49, pp. 433458.

Reagans, R. and E. W. Zuckerman (2001). 'Network, diversity and performance: The social capital of R\&D teams.', Organization Science, 12, pp. 502-518.

Scott, J. A. (2000). Social Network Analysis., Sage Publications, Thousand Oaks, CA.

Simsek, Z. (2009). 'Organizational ambidexterity: Towards a multilevel understanding.', Journal of Management Studies, 46, pp. 597-624.

Simsek, Z., C. Heavey, J. F. Veiga and D. Souder (2009). 'A typology for aligning organizational ambidexterity's conceptualizations, antecedents, and outcomes.', Journal of Management Studies, 46, pp. 864-894.

Smith, W. K. and M. W. Lewis (2011). 'Toward a theory of paradox: A dynamic equilibrium model of organizing.', Academy of Management Review, 36, pp. 381-403.

Taylor, A. and C. E. Helfat (2009). 'Organizational linkages for surviving technological change: Complementary assets, middle management, and ambidexterity.', Organization Science, 20, pp. 718-739. 
Tsai, W. (2001). 'Knowledge transfer in intraorganizational networks: Effects of network position and absorptive capacity on business unit innovation and performance.', Academy of Management Journal, 44, pp. 996-1004.

Vanhaverbeke, W., V. Gilsing, B. Beerkens and G. Duysters (2009). 'The role of alliance network redundancy in the creation of core and non-core technologies.', Journal of Management Studies, 46, pp. 215-244.

Wang, C. L. and M. Rafiq (2012). 'Ambidextrous organizational culture, contextual ambidexterity and new product innovation: A comparative study of UK and Chinese high-tech firms.', British Journal of Management, forthcoming. 
Table 1: List of interviews and position of interviewees

\begin{tabular}{|l|l|l|}
\hline \multicolumn{1}{|c|}{ Number of interviews } & \multicolumn{1}{c|}{ Unit } & \multicolumn{1}{c|}{ Function } \\
\hline 1 & Headquarters & HR director \\
\hline 2 & Division Headquarters & HR manager \\
\hline 1 & Division Headquarters & Control manager director \\
\hline 3 & Division Headquarters & 3 operational directors \\
\hline 2 & Region A & Director \\
\hline 6 & Region A & 6 managers (all) \\
\hline 7 & Region A & 7 employees \\
\hline 2 & Region B & Director \\
\hline 1 & Region B & Manager \\
\hline 2 & Region B & 2 employees \\
\hline 2 & Region C & Director \\
\hline 4 & Region C & 4 managers \\
\hline
\end{tabular}


Table 2: Characteristic of social network connections at ComInt

\begin{tabular}{|c|c|c|c|}
\hline Type of network & $\begin{array}{c}\text { Hierarchical level } \\
\text { Manager (Ma), } \\
\text { Expert (Ex), } \\
\text { Employee (Em) }\end{array}$ & $\begin{array}{c}\text { Function } \\
\text { Technician (Te), } \\
\text { Sales (Sa), } \\
\text { Administration (Ad) }\end{array}$ & $\begin{array}{c}\text { Proportion of } \\
\text { respondents }\end{array}$ \\
\hline Contact & Ma, Ex, Em & Te, Sa, Ad & 0.93 \\
Control & Ma, Ex & Te, Sa, Ad & 0.53 \\
Influence & Ma, Ex, Em & Te, Sa, Ad & 0.67 \\
Help & Ma, Ex, Em & Te, Ad & 0.47 \\
Trust & Ex, Em & Te, Sa & 0.27 \\
\hline $\begin{array}{c}\text { Contact, Control, } \\
\text { Influence, Help, Trust }\end{array}$ & Ex, Em & Te, Sa & $\mathbf{0 . 2 7}$ \\
\hline
\end{tabular}


Figure 1: A model of individual, external social capital and business unit ambidexterity

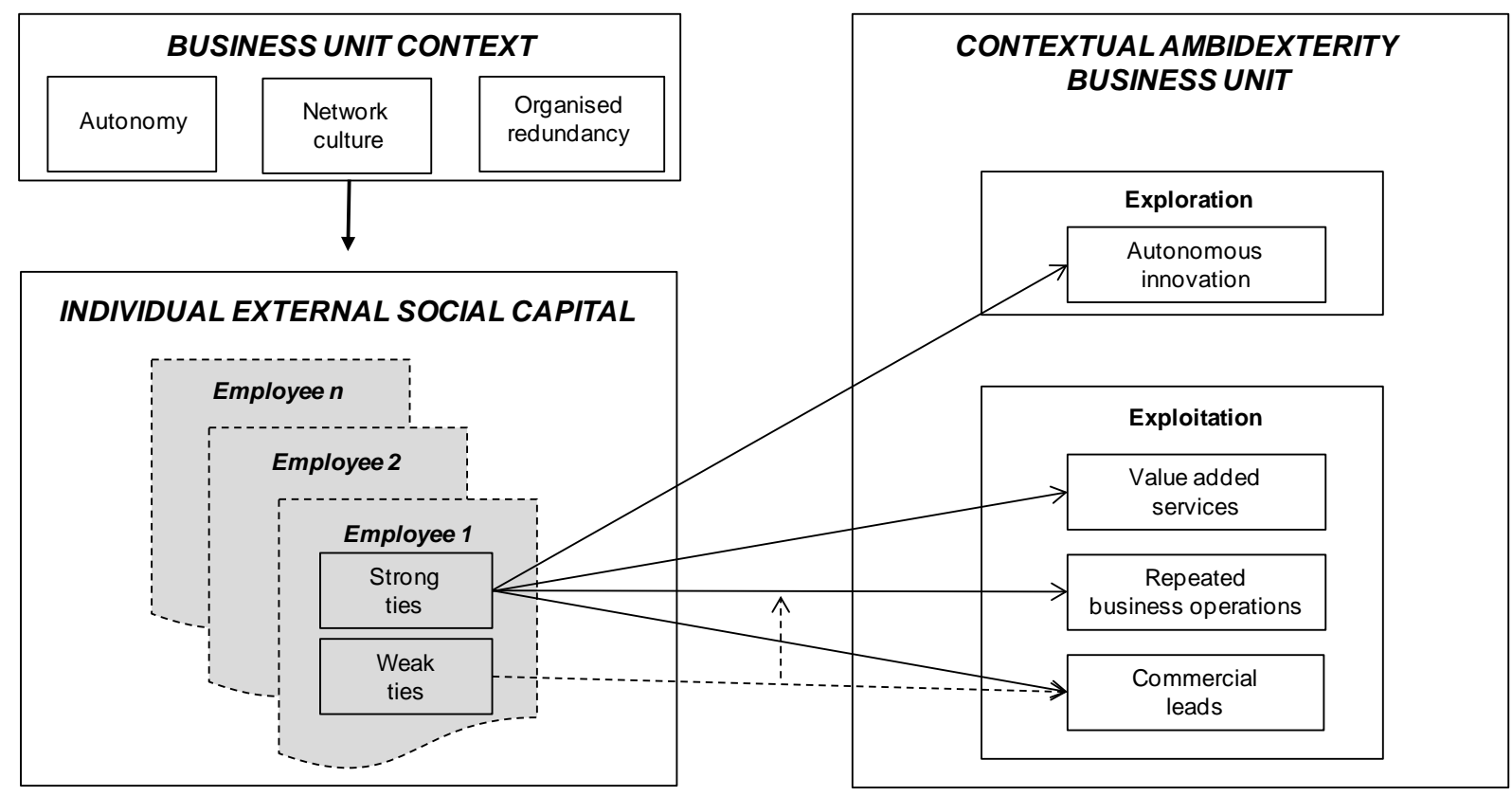




\section{Appendix: Sociometric questionnaire}

We analysed several social networks at ComInt regarding 5 dimensions: work contact, control, influence, help/advice, and trust. The questions were as follows:

- $\quad$ Contact: Which people do you have frequent contact with at work?

- Control: Which people exert direct or indirect control on the result or the quality of the work you have done? Which people do you exert direct or indirect control over concerning the result or the quality of their work?

- Influence: Which people‘s declarations, suggestions or judgment, in general or on a specific point, will change the way you act? Which people modify the way they act because of your suggestions or judgment in general or on a specific point?

- Help and advice: Which people give you advice or help you on specific points? Which people do you give advice or help to on specific points?

- $\quad$ Trust: Which people would you trust to deal with a delicate professional matter? 